\title{
Taboo and Cultural Psychology in Cantonese
}

\author{
Xiaoyan Cao \\ School of Literature \\ South China Normal University \\ Guangzhou, China
}

\begin{abstract}
Guangdong province has a well-developed commercial economy with a large population. In the long-term development of Cantonese, there have many taboos. Taboos are linguistic customs that have local dialects or social dialects. Many taboo words in Cantonese are often ignored by the public because of their meaning or pronunciation. Instead, they are often counter-productive euphemisms. For example, people in Guangdong say that "pig blood" is "pig red", "vacant house" is "Jiwu", "aunt" is "boyou" and so on. At the same time, these taboo words in daily life reflect the thick commercial culture of Guangdong province to a certain extent. Also, they reflect people's fear of ominous things and their hope for a better life.
\end{abstract}

Keywords-Cantonese; taboo; characteristics; cultural psychology

\section{INTRODUCTION}

Taboo refers to the ancient people's superstition. In different occasions, there will have different taboos. If people say it in an accidental case, there will bring corresponding retribution. There are different taboos in different regions. Because of the different influences of religious beliefs, folk customs, and education, people constantly improve the taboo in their lives. Up to now, taboo has become cultural heritage of language. These taboos have also been spread by the Chinese people for thousands of years.

\section{THE DEFINITION OF TABOO}

According to historical records, the earliest record of taboos in Chinese could be tracked back to the Western Zhou Dynasty. In "Book of Rites", "If people enter the border, they should and ask the taboo. If they enter the country, they should ask the custom. If they visit the friend's family, they should ask the rule." In "Rites of Zhou", "The rulers would know the mistakes. They would avoid the taboos according to the Emperor's text. And then, they would know the customs." This shows that the ancients attached great importance to taboo customs. In Ban Gu's "Han Shu- Yi Wen Zhi - Yinyang" of the Western Han Dynasty, "When there are difficulties, they are imprisoned. They would be stuck in small details. And they wouldn't try hard. And they just wait the arrangement. In "History of the Later Han Dynasty-Langyi Zhuan", "I grew up in the grass. And I do not know taboos. I would disclose all the bad things and write them down." It can be seen that the word "taboo" also appeared in some historical materials in Han dynasty. In
Wang Fu's "A treatise on the latent man-Zhonggui" of the Eastern Han Dynasty, "If you are afraid of the ominous things, you should understand all the taboos. If you believe that the door isn't sturdy and durable, we should use the iron. Due to few taboos, it would have some obstacles. They would be arrogant with financial crisis. And they wouldn't have the heart of the public." In Ying Xun's "customZhengshi-Yuanyuan of Pengcheng" of the Eastern Han Dynasty, "There are many taboos in the folk. If people were born in May, or they have other two brothers, they would hurt their parents. And they should take filial piety. And then, it would be good with each other." In Su Zheng's "Taboo of the Ming Dynasty" of Tang Dynasty, "According to Yinyang's note, it would have many taboos of the building." In Yan Zhitui's "The Family Instructions of Yan-Health Maintenance" of the northern Qi, "If he loves the gods, protects breath, adjusts the food, and follows the rules, they should put the drugs. And they would have no obstacles." In Xie Zhaozhe's "Wuzazu-Renbuyi" of Ming Dynasty, "People don't believe the doctor's advice. And they would use different wood, obey the taboos, get up at the time, and adjust the food. And then, the ominous things would be changed into good things." It can be seen that the "taboo" appears in the Western Zhou Dynasty. And the "taboo" was explicitly proposed in the Western Han Dynasty. Since then, it has been used by later generations. In Xu Shen's "Shuowen Jiezi" of the Eastern Han Dynasty, the word "forbidden" was interpreted as "taboo". And the word "Ji" was interpreted as "nasty evil". From this point of view, the "taboo" should be used in ancient times as the meaning of "prohibited taboo words and deeds".

Taboo belongs to the category of linguistic taboo. And it is language custom that has local dialect or social dialect. The principle of taboos generally drives from good fortune, rituals, utilitarianism, honor and disgrace. To a certain extent, language taboos are the reflection of people's superstition and worship on language for a long time. People generally believe that there is a mysterious connection between language and things. And ominous words can often lead to ominous events. People's taboo on bad things has turned into avoidance of language. So what is a taboo? So far, there is no universally accepted definition in the academic circle. However, it is generally believed that the current taboo language in any society refers to those topics, articles, or facts that have sacred or inviolable nature due to social customs or emotional factors. It cannot be mentioned, touched, or used by the general public. 


\section{TABOO IN CANTONESE}

Different regions have different local dialect vocabulary. Similarly, in Cantonese, there is also a kind of linguistic custom that has local characteristics - taboo language.

\section{A. Classification}

Due to the commercial development and the auspiciousness of the provincial and port areas, the taboo language in Cantonese is the largest in all parties of dialects. The taboo words in Cantonese can be divided into two categories according to their meaning and pronunciation: meaning taboo and homophonic taboo.

1) Meaning taboo: In certain social customs, the meaning of words would make people remember ominous things. That is to say, it is a taboo. People often use corresponding words or opposite words to avoid taboo in daily life. For example, "pig blood" and "blood" have the meaning of "red opaque liquid in the circulatory system of humans or animals". It is easy to think of red ruins and infelicity. And "red" can exorcise evil spirits. Cantonese does not say "blood". They would use the word "seeing red" instead of "seeing blood". Also, they would use the word "pig red" instead of "pig blood". In "pork liver", "chicken liver" and "ganbei", "gan" doesn't have the meaning of water. Cantonese believe that water brings them money. The word "gan" is equivalent to no money. Cantonese changed the word "gan" (千). And they would use the word "pork liver" (猪閏), "chicken liver" (鸡膶) and "dried bean curd" (豆 腐膶). "Cheers" is called "Yinsheng" (饮胜). In the word "bitter gourd", it has the meaning of "hardness". Generally, Cantonese called "bitter melon" as "lianggua" (凉瓜). There is also "bitter medicine" in Guangdong. There is also the word "Be mad" and "Laugh to death" in Cantonese. In order to avoid "death," Cantonese also use "stimulate me" and "laugh to growth".

2) Homophonic taboo: Under certain social conventions, the pronunciation of words would make people remember ominous things. And that is homophonic taboo. People often use words similar pronunciation to avoid taboos in daily life. For example, "empty", "empty house". The "Kong" and "Xiong" have same pronunciation in Cantonese. The word "xiong" is ominous. Many words related to "kong" should be replaced by "Ji". Cantonese renamed "empty houses" (空 房子) as "Jiwu" (吉屋). And "empty" should be replaced by "fortune". In Cantonese, "shi" (蚀) is equal to "profit and loss". And these words are businessmen's taboos. The "tongue" and "chi" were changed. "Pig Tongue" was changed to "zhuli" (猪脷). It has taken the meaning of fortune. And "eating" was changed into "aifan" (嗌饭). For Cantonese who love to play mahjong, the word "lose" is also a taboo. "Si" and it have the same pronunciation. They can't say "si". Cantonese call "towel gourd" as "shenggua" (胜瓜). Also, they can't say "shu". When they read books, they would use the word "seeing wins" (看赢). In Cantonese, "mu" (母) and "mu" (无) have same pronunciation. It is unlucky. Generally, they do not say it. When visiting a friend's home, "aunt" should be called "Bai You". In Cantonese, "gan" (杆) and "jiang" (降) have the same pronunciation. The "jiang" is to reduce something. They change "gan" into "sheng". Guangdong's famous "zhugan noodle" is generally called "Jooksing noodle". "San" (伞) and "san" (散) have the same pronunciation. People would remember the loss. Cantonese would change "san" (伞) into "zhe" (遮). The umbrella could be changed into "yuzhe".

\section{B. Taboo Ways}

In daily life, people are afraid to hear the taboos. They fear that these words will lead to the real evil. However, in the interpersonal communication, people sometimes need to express ominous content. It is necessary to use other ambiguous or neutral words instead. This kind of flexible expression has the following two methods.

The first is to use antisense words to replace inauspicious words. That is "blessing words". This method is commonly used in taboo language. For example, Cantonese use the word "jishengwo" (激生我) instead of "gasing to me" (气死我). They would use the word "laughing to growth" (笑生我) instead of "laughing to death" (笑死我). In Cantonese, "gan" (杆) and "jiang" (降) have the same pronunciation. They change "zhugan" (竹杆) to "zhusheng" (竹升). The "Kong" and "Xiong" have same pronunciation in Cantonese. They use the word "Ji" (吉) to replace the word "kong" (空). The word "renting out empty rooms" would be changed into the word "renting out jiwu" (lucky rooms", 吉屋). The word "mussel" (dancai, 淡菜) would be changed into the word "wangcai" (旺菜). The word "mussel" (dancai, 淡菜) refers to dried food without salt. The word "mussel" (dancai, 淡菜) is mainly called by the southerners. The northerners would call it "haihong" (海红). The word "dancai" (mussel, 淡菜) would make people feel dissatisfied. And they renamed it as "wangcai" (旺菜). Cantonese people called the closing of the business at night as "dayang" (打烊). The businessmen would avoid the word "closing doors" (关门). And it has the meaning of bankruptcy. "Yang" (烊) means molten metal. In ancient times, the shopkeepers collected the silver pieces during the day and melted them into large ingots at night. They had to "dayang" (打烊). The meaning of "dayang" (打烊) is not to closing the door. It is simply a matter of fortune. If they really have the bankruptcy, it cannot be called "closing the door". And it should be the word "stopping business". It means that the businessmen would take a break and start over.

The second is to use related or similar names of things instead. For example, "red" can drive evil spirits out of ghosts. Cantonese does not say "blood", "seeing blood". They would use the word "seeing red" instead. The word "pig blood" was changed into "zhuhong" (猪红). Generally, Cantonese would call coffin as "shoumu" (寿木). It would avoid the meaning of "death". The "chicken claw" was renamed as "fengzhua" (凤爪). The "chicken" in the zodiac was known as "xiaofeng". "Death" was renamed "to pass through". The testate of the dog is aromatic. Cantonese called "dog meat" as "spicy meat". 
Cantonese people prefer to "speak good words". If you really say taboos, you just need say "great fortune". The meaning is to avoid the damages. If you are a child, you can say that "never mind, I am just a child. And I don't know anything."

\section{CUltural PSyChOlOGY}

Language is the carrier of culture. Also, it would be influenced and restricted by culture. To a certain extent, it also reflects the psychological characteristics of people under certain conditions.

\section{A. Cultural Connotation}

The relationship between language and culture is very close. Language is the carrier of culture and an important part of culture. Language is a mirror that reflects social reality and a tool for cultural heritage. At the same time, language is influenced and restricted by culture. Culture is the foundation of language formation and development. And it is the source of symbolic meaning of language vocabulary. Language and culture would interact and complement each other. Therefore, understanding language must understand culture. Also, understanding culture can understand language. The taboo language in Cantonese is closely related to Guangdong's business culture. Its formation has been affected by the business culture. Also, it reflects the commercial culture to some extent.

Guangdong province is next to the South China Sea. And it is backed by the Five Ridges. The river network stretches across the territory of Guangdong province. And the Pearl River Delta is the meeting point for the East, West and North Rivers. It has fertile land and rich products. In ancient times, transportation in Guangdong depended on ships. And the exchange of goods took place in the market along the rivers. After several years, many towns were gradually established. Meiling Mountain was developed in the Tang Dynasty, exchange of commodities between the north and the south was connected. There were many foreign businessmen who came here to do business. In the Qing Dynasty, Guangzhou was once the only foreign trade port in the country. After the Opium War, coastal ports such as Guangzhou, Jiangmen, Shantou, and Huizhou were successively opened to the outside world. Affected by the overseas culture, businessmen's thinking was more open and the business developed rapidly. As a result, Guangdong has formed strong commercial culture that existed in ancient times. On the basis of the continuous prosperity of this business culture, there are a large number of taboos in Cantonese. For example, the Cantonese called the closing of the store "dayang" (打烊). "Zhuganmian" (竹杆面) is called as "Jooksing noodles". The word "renting empty house" could be the word "to rent Jiwu" and so on.

\section{B. Psychological Refraction}

1) Anxiety and fear: The basic principles of social psychology tell us that when there is a clear danger, people will have fear. When the danger is unclear, people will have anxiety. Among language taboos, people would feel anxiety and fear of ominous things. Due to ancient ignorance and modern superstition, people often equate language with the things represented by language. And they may think that there is some necessary connection between language and the things represented by language. Psychologically, they would have the anxiety for taboos. The sense of fear has evolved to replace embarrassing language with anxiety. Fear would have fear-control reactions. That is, it may have psychological and behavioral fear-control reactions. And it would have the thoughts and behaviors of avoidance. Therefore, the taboo language in Cantonese is the refraction of people's anxiety and fear to a certain extent.

2) To avoid aggression: Due to superstitious ideology, people believe that the good, bad, and evil are arranged by fate. And this leads to the notion of avoiding evils. The folks have the fear of "being fierceness and mischief". Therefore, there are taboos for "not to say ghosts under the lights, and not to mention wolves in the mountains". Therefore, in people's daily life, there is euphemism related to the lucky psychology. Through the use of euphemism, the author tries to pray for auspiciousness in speech activities. At the same time, there are also some auspicious words. For example, in Guangdong province, there is a famous dish called "hair-like seaweed fish ball". And the homonym is "facai yuwan". During the Spring Festival, every family buys a pot of kumquat and takes the "Ji" to replace "orange". It shows the fortune. On New Year's Day, they should buy the rooted lettuce. And it shows the meaning of "benefit". Also, it has the meaning of "head and tail". In New Year, they would eat rice cake. And they have the will of "having the growth". These auspicious words reflect people's hope and longing for a better life in the future to some extent. Therefore, the taboo language in Cantonese is the refraction of people's anxiety and fear to a certain extent.

\section{CONCLUSION}

Taboo is linguistic phenomenon and social phenomenon. Its formation is mainly the result of the combination of various social factors. The taboo language in Cantonese is embodied in all aspects of social life. Understanding and analyzing the cultural and psychological connotation of taboo language helps to understand the development and changes of human society. And it would deepen the understanding of Chinese language phenomenon and cultural background. At the same time, correct use of taboo language will also promote the effectiveness of communication among people. This article attempts to analyze the taboo language in Cantonese and analyzes its production, linguistic features and cultural psychology. This will enable people to have a deeper understanding of the taboo language in Cantonese.

\section{REFERENCES}

[1] Cao Zhiyun. Language differences and cultural psychology [M]. Hebei: Hebei People's Publishing House, 1994. 曹志耘.语言差异与 文化心理[M].河北: 河北人民出版社,1994 年。 
[2] Wan Jianning. Taboo and Chinese culture [M]. Beijing: People's Publishing House, 2001. 万建宁.禁忌与中国文化 [M]. 北京: 人民 出版社, 2001 年。

[3] Li Zonggui. Introduction to Chinese culture [M]. Guangdong: Sun Yat-sen University Press, 1988. 李宗桂. 中国文化概论 [M].广东: 中 山大学出版社, 1988 年。

[4] Du Shichun. Psycholinguistics [M]. Shanghai: Shanghai Education Press, 1985. 杜诗春.心理语言学 $[\mathrm{M}]$. 上海: 上海教育出版社, 1985 年。

[5] Shen Xiaolong. Modern thinking on language and culture [M]. Henan: Henan People's Publishing House, 2000. 申小龙.语言和文化的现代 思考 $[\mathrm{M}]$.河南: 河南人民出版社, 2000 年。 